\title{
ESTILOS DE VIDA E INDIVIDUALIDADE
}

\author{
Mauro Guilherme Pinheiro Koury \\ Universidade Federal da Paraíba - Brasil
}

Resumo: Este artigo apresenta e discute a questão dos estilos e modos de vida na contemporaneidade. Tem como ponto de partida o conceito de liberdade individual na relação entre a cultura subjetiva e a cultura objetiva de Georg Simmel, para pensar os processos de individualidade e de diferenciação na sociedade contemporânea.

Palavras-chave: cidade, estilos de vida, individualidade, modos de vida.

Abstract: This article presents and discusses contemporary life styles and life ways. It's starting point is the concept of individual freedom in relation to subjective culture and the objective culture of Georg Simmel, is used for thinking differentiation and individuality processes in contemporary society.

Keywords: city, individuality, styles of life, ways of life.

A questão dos estilos de vida está relacionada à questão do processo de individualidade na sociedade. Simmel discute essa questão através do conceito de liberdade individual advinda com o desenvolvimento social na expansão do sistema capitalista a partir do século XIX, e indica, sobretudo, a cidade e a realidade urbana como locus específico dessa liberdade.

A liberdade individual, tão bem tratada por Simmel em seus ensaios, é trabalhada socialmente associada aos vínculos interacionais entre indivíduos. É na interação entre indivíduos sociais que essa liberdade se faz presente, compondo o que ele chamou de cultura subjetiva em uma realidade urbana.

Essa cultura subjetiva, formada na troca interacional entre indivíduos possuidores de um quantum de liberdade, permite o aumento da diferenciação entre cada um deles e nos grupos e arranjos sociais por eles organizados, complexificando a relação e a vida na cidade. $O$ conceito de diferenciação, desse modo, em Simmel, está ligado ao conceito de individualidade que, por sua 
vez, satisfaz a uma complexificação e desenvolvimento da cultura subjetiva no locus urbano onde se realiza.

Esse jogo entre liberdades em relação não se satisfaz em um quadro puramente harmônico, antes pelo contrário, o processo de constituição de uma cultura subjetiva se vale da diferenciação individual predisposta pela liberdade vivenciada pelas pessoas em troca, e se aliança em formatos conflituais mais ou menos estáveis, compondo grupos, classes, instituições, estilos e modos de vida, como cultura objetiva.

A cultura objetiva, portanto, se apresenta socialmente como resultado das trocas subjetivas dos indivíduos em um jogo interacional, compondo interesses e divergências, tendências, estilos e modos de viver. O que amplia e complexifica ainda mais o processo de individualidade, produzindo um aumento e um crescimento da cultura subjetiva, e objetivando-se em uma sequência de produção objetiva da cultura e dos modos de viver social. A diferenciação, se, de um lado, produz encontros e novas formas de inserção individual no urbano, de outro, faz brotar focos de divergência e conflito que estimulam uma maior diferenciação e novos olhares sobre si mesmo e os outros.

O conflito, desse modo, é a categoria analítica principal, em uma leitura atenta, de Simmel. Isso na medida em que as procuras, satisfações e insatisfações dos indivíduos em interação são configuradas em um dado agrupamento social qualquer, de uma sociedade urbana onde melhor se realizou essa busca pela autonomia individual, enquanto limites e fronteiras construídas ou estabelecidas nas relações vinculares dos sujeitos em jogo, através da objetivação da cultura; e o seu sufocar, ou melhor, a busca de contenção de sua subjetividade, no interior dessa cultura objetiva conformada, e os motins encobertos, em seu interior, pela ampliação da cultura subjetiva no refreamento objetivo dos vínculos estabelecidos.

Diferente de Durkheim, ${ }^{1}$ por exemplo, para quem a sociabilidade é um sinônimo de contenção dos impulsos, e a liberdade civilizatória viria como consequência dessa domação de impulsos, os pontos de partida de uma socialidade, em Simmel, são sempre motivados pela alegria e pela festa da participação com os outros, na quebra da homogeneidade comunitária que sufocava

1 Ver a resenha de Durkheim (2002) sobre a Filosofia do dinheiro de Simmel, onde as diferenças entre os dois autores contemporâneos sobressaem. 
as individualidades, nas descobertas da diferença e nos conflitos abertos pelas admoestações da diferença na conformação do grupo, dando espaço para uma ampliação da liberdade individual.

O confronto entre a objetividade e a subjetividade, ou entre a cultura objetiva e a cultura subjetiva - as primeiras buscando domar as subjetividades em jogo vincular e as segundas procurando ampliar as margens da liberdade de expressão pela diferenciação crescente -, é para ele, então, o ponto nodal por onde se devia metodologicamente compreender a formação sempre tensa da relação indivíduo e sociedade (Koury, 2004, 2009).

Leitor assíduo de Marx, outro seu contemporâneo, acredita que o processo de cultura está inscrito na dialética do sujeito e do objeto, que marcam polos adversos e indissolúveis nesse processo. Diferente de Marx, porém, que confiava em uma reconciliação desse processo na sua construção e constituição ontológica do sujeito no mundo, através do desenvolvimento das forças produtivas, Simmel estabelecia críticas ao que ele considerava uma visão nostálgica, e mesmo melancólica (Waizbort, 2000) da reconciliação modificada de um passado de indiferenciação, pela determinação histórica, e abria possibilidades conceituais e investigativas para a ampliação dessa dialética, que se faria sempre pela busca de um grau a mais de autonomia dos indivíduos, ou seja, da cultura subjetiva, no interior de uma cultura objetiva dada; onde não haveria conciliação possível nessa dialética e, sim, um conflito sem fim, indeterminado, na configuração social das relações entre sujeito e objeto. Nesse ponto residindo o que ele chama de tragédia da cultura (Simmel, 1998).

A tragédia da cultura, assim, diz respeito à possibilidade da cultura objetiva - criada nas trocas interacionais dos indivíduos livres formando campos de interesses e de maior diferenciação, como cultura subjetiva -, submeter as subjetividades individuais e coletivas livres no jogo interacional aos interesses da própria objetificação, onde se realizam socialmente. Para Simmel (1907), em sua leitura sobre o dinheiro na sociedade capitalista, transformado em um deus ex machina na cultura objetiva contemporânea, ele tende a reduzir e igualar tudo e todos a um mesmo equivalente, impondo-se objetivamente contrário à cultura subjetiva e à liberdade individual, isto é, à individualidade e diferenciação delas advinda na troca interacional.

Isso amplia o domínio da cultura objetiva sobre a cultura subjetiva, desvirtuando a complexificação e diferenciação crescente de individualidades em individualismo. O choque gerado na relação entre as individualidades e suas 
diferenciações e o individualismo, este último associado ao empobrecimento da cultura subjetiva e ao consumismo, tendo o dinheiro como equivalente único de sua expressão, dilui as expressões da liberdade em uma guerra por ter.

O próprio conceito de arte, produto por excelência da cultura subjetiva, se vê, desse modo, corroído e subsumido pela expressão monetária que a reduz a um valor de troca e comercialização. Benjamin (1985), um autor influenciado por Simmel em seu processo formativo, no seu ensaio sobre $a$ obra de arte na era da reprodutibilidade técnica, tocará no mesmo teclado já advertido por Simmel no final do século XIX.

De uma forma semelhante, autores americanos, também influenciados por Simmel e que configuraram a Escola de Chicago, que brilhou no cenário americano nos quarenta primeiros anos do século XX, como Georg Mead (1934), Robert Park (Park; McKenzie; Burgess, 1925) e outros, insistiam na diferenciação como produto da cultura subjetiva e na sua objetificação em instituições e grupos e sistemas de interesse. Bem como no conflito originado pelo choque entre esse processo ininterrupto de individualidades, advindas da cultura subjetiva, e a cultura objetiva socialmente produzida pelas interações entre indivíduos em instituições e sistemas de interesses.

Diferente da visão melancólica da leitura de Simmel, feita por Benjamin (1985), indicaram no choque entre cultura subjetiva e cultura objetiva a possibilidade da própria complexidade de produção de novas diferenciações. Um sistema de interesses formado por subjetividades individuais em jogo no interior de um projeto comum, assim que cristalizado em uma instituição ou grupo, gerava, sempre, dissensos e provocava rupturas para uma nova forma de individualidade que já não se adequava às normas cristalizadas do grupo ou instituição que ajudou a gerar. Formatando novos projetos e seguidores na busca conflitual de um novo universo de possibilidades que os adequassem objetivamente no social.

Se em Benjamin (1985) é possível ler a melancolia da subsunção das massas à cultura objetiva através da alienação, e apenas uma saída coletiva via revolução social e aniquilação do capitalismo para uma nova sociedade e um novo sistema social: o socialismo; na leitura proposta pela Escola de Chicago, é na ação social individual, é na produção de individualidades geradoras de crescentes diferenciações, é na própria diferença, enquanto conceito de liberdade e produção de cultura subjetiva, que se encontravam o limite de cada ação social e a superação desses limites no jogo interacional de um social qualquer. 
Colocando o conflito como palco principal por onde se desenrolam ações subjetivas e a construção objetiva do social, em uma cultura determinada, a Escola de Chicago discute e inova os estudos sobre a cidade no início do século XX, através de um olhar investigativo que procura ver o urbano como um local por excelência de ampliação das liberdades individuais, dos projetos e modos de vida das populações nele inseridas; e na luta cotidiana pela busca de inserção e ampliação do tecido urbano para novas configurações que permitissem compor novos estilos e novos projetos e projeções individuais e grupais no seu interior. Ao mesmo tempo em que se abria a verificação do choque desses novos projetos e olhares no interior das instituições cristalizadas, gerando rupturas, de um lado, e coerções e disciplinamento, por outro.

Esse novo aporte metodológico, desse modo, abria-se para a incorporação das pulsões individuais e grupais em busca de adequação social ou de rejeição ou superação do societário vivido. Bem como do entendimento da legitimação institucional e de sua regulação aos indivíduos e grupos que dela fazem parte, como componentes de sua reprodução. No conflito desses dois processos se organizaria o novo, como uma sequência ininterrupta de mudanças e permanências no social e no individual em uma cultura objetiva regida e contestada pela cultura subjetiva, no jogo incessante de composição de um societário dado.

Se modos e estilos de vida tendiam a conflitar com outros modos e estilos de vida presentes na reprodução contínua das instituições, formando novos jogos de interesses e projetos e sentindo-se abafados pelas normas e disciplinas constituídas, é no próprio seio dessa composição que se exerciam e se exercitava a novidade desses novos modos e estilos, como produção de tendências originais no interior das já normatizadas. O que compõe uma dialética do novo no interior do arranjo societário já instituído e cristalizado.

O corpo social de uma cultura urbana, desse modo, é depositário de uma enormidade de modos e estilos de vida que, por sua vez, produzem, rejeitam, recompõem outros tantos, e, ao mesmo tempo, associam-se ou conflitam entre si, nas projeções de configurações por eles almejadas, nos jogos interacionais a que se viam submersos. Sem falar, ainda, e, contudo, que esses mesmos modos e estilos de vida, em si, não eram alheios a conflitos, pelo contrário, viam-se, exerciam-se e objetivavam-se através deles.

Os iguais ou semelhantes em um tempo e espaço singular, no momento de perseguição de um projeto, podiam tornar-se adiante em dessemelhantes e

Horizontes Antropológicos, Porto Alegre, ano 16, n. 33, p. 41-53, jan./jun. 2010 
diferentes, quando abafados ou oprimidos pelas normas do grupo ou instituição que ajudaram a soerguer, e se conformavam ou buscavam novos espaços para exercitarem a própria liberdade e diferenciação que já não mais viam e sentiam no grupo de que faziam parte. Originando apatias e anomia ou críticas, rupturas, coerções e afastamentos, resultando ou não em novos projetos ou ações projetivas para uma nova inserção social.

Esse jogo contínuo de diferenciações, em ações sociais sempre indeterminadas e movidas por instâncias projetivas e projetadas em novas inserções e registros sociais, permitem ou possibilitam a ampliação e ajudam a complexificar a cultura subjetiva de um dado espaço-tempo, compondo novas performances individuais e grupais dentro de um estilo e de um modo de vida existente, permitindo sua diferenciação. E, nesse processo, também, sua subsequente fragmentação.

Fragmentação em vários campos de onde germinavam modos, estilos e tendências singulares: se lidos em relação aos passados de onde foram compostos, dentro de uma análise genética; ou, de onde localizavam as bases de sua evolução, ou a rechaçavam em ondas de estranhamentos provocados pela ruptura com esses passados, que não reconheciam ou não mais entendiam como fontes de sua emergência. Os fazendo advogar a sua superação e a inauguração de um novo tempo-espaço onde poderiam germinar como instituintes.

A vida urbana, principalmente nas grandes cidades contemporâneas e não só nas metrópoles, é o local propício para essa diferenciação, que se distingue ininterrupta e indeterminadamente na constituição de modos e estilos de vida sempre singulares e que jogam o jogo interacional dentro de um diálogo diacrítico consigo mesmo e com os demais. O que complexifica a individualização e a individuação de indivíduos e grupos em um social dado, ampliando a cultura subjetiva através da fragmentação de cada novo desempenho, no interior de um dado estilo ou modo de vida instituído.

É importante, aqui, o retorno a Simmel e a sua leitura do Capital de Marx, através do reforço da superestrutura como base analítica para se pensar o poder do dinheiro, como o único equivalente de troca capaz de subsumir a liberdade individual a um valor monetário de troca, o coisificando e o igualando a outro produto qualquer, na sociedade moderna capitalista, para entender como essa diferenciação crescente da vida social contemporânea, ao mesmo tempo em que alicerça o homem em uma individualidade cada vez mais complexa, estimulando a sua criatividade e liberdade, leva esse mesmo homem a 
abrir mão dessa liberdade em troca de um individualismo consumista e a uma solidão cada vez maior.

Sennet (1998), no seu já clássico $O$ declínio do homem público, demonstra como a modernidade trouxe uma abdicação crescente do público em relação ao privado, e como esse processo vem trazendo consequências sociais e culturais e políticas na esfera da sociabilidade e das trocas interacionais. Norbert Elias (1990, 1993), por seu turno, indica o crescente processo da discrição como uma das características do homem ocidental contemporâneo, mostrando como o indivíduo moderno incorporou a disciplina social, em um processo de autodisciplina que o impede ou o dificulta de manifestar suas emoções em público, criando uma esfera de distanciamento em relação ao outro.

O que faz esse outro ao mesmo tempo objeto de medos e objeto de curiosidade à distância, que estimula a desfaçatez, o olhar pelo buraco da fechadura, ao constrangimento do outro, e, simultaneamente, a hábitos exibicionistas, de mostrar-se em sua privacidade corpórea ou mental através de jogos de visões: como as câmeras colocadas em locais íntimos e permitidas a outros verem intimidades cotidianas de si, de forma gratuita ou remunerada, através da internet, ou nas exposições dissimuladas em chats ou centros de relacionamento, onde podem ser ao mesmo tempo tudo, todos e ninguém. Onde é possível a liberdade da dissimulação e da exposição de si, ao mesmo tempo em que se prolonga a solidão e o nonsense e a pobreza emocional da vida cotidiana em que se encontra.

Outros autores, contudo - sem deixar de mencionar essa tendência para a solidão e para a pobreza emocional da vida cotidiana na modernidade -, estudando o processo de interação em meios como a internet (Cadoz, 1994; Lemos, 2007), mostram uma riqueza e uma explosão de criatividade e uma polissemia de estilos de vida que vem modificando os hábitos do cotidiano do tecido urbano. E, inclusive, indo além dele, compondo novas formas de interação globalizadas que interferem nos próprios modos de vida de quem os usa, seja em formas individuais ou grupais.

Falam das redes sociais e das possibilidades de agregar singularidades dispersas e quebrar, inclusive, barreiras antes difíceis de serem transpostas, através de novas e ininterruptas fontes de informações, que, ao mesmo tempo em que estabelecem as bases de uma ampliação de recursos novos para testar o mundo, individual, grupal e global, permitem revisões e encontros com os mundos próprios singulares, ajudando a refazer percursos, a acolher novos

Horizontes Antropológicos, Porto Alegre, ano 16, n. 33, p. 41-53, jan./jun. 2010 
dados interpretativos sobre sua própria história, etnia, tendência. O que amplia a singularidade de suas próprias atuações agora em um tecido genético mais conforme e os integrando, simultaneamente, em uma rede maior, onde estilos, tendências, modos de vida são testados a todo instante como adequados ou não para serem intercambiados em trocas interativas, e assumidos a partir de uma releitura própria - pessoal ou grupal -, ou compartilhados na sua diferença, como outras formas de viver de outros grupamentos ou pessoas (Martins, 2004).

É possível, através dessas redes, a organização de movimentos específicos de um único ato, como os encontros acontecidos em várias cidades brasileiras e mundiais, desde o ano 2000, onde um sem-número de internautas aparecem em um dia tal e em um horário tal, em um local predeterminado, vestindo um determinado tipo de roupa, ou de uma determinada cor, para fazerem determinada performance pública. Pessoas que nunca se viram, a não ser nas trocas virtuais, de repente estão juntas e compartilhando um mesmo ato e vivendo uma mesma experiência pública de exposição: artística, de protesto, ou simplesmente de alegria de estar junto compartilhando e expondo um mesmo pensamento em sintonia para si, para o grupo e para a comunidade ao redor que observa estupefata a atuação que quebra a monotonia do lugar onde se realiza e faz pensar.

Provocam, assim, intervenções urbanas, ou instalações no urbano, deixando marcas simbólicas singulares no espaço e tempo sociais. Acabando o ato, cada qual se recolhe individualmente ou em grupos ao seu cotidiano, havendo ou não novas performances no mesmo estilo.

É possível, também, a organização de redes que comportam instrumentalidades de ações individuais e coletivas e que procurem organizar, agilizar e estimular ações em prol de identidades genéricas: cortes de cabelo, modas, tipo específico de música ou de grupo musical, comidas especiais, tanto quanto de identidades profissionais, étnicas, de gênero, de ambientalistas, e outras tantas, ocorrendo a incorporação de uma multiplicidade de atores que buscam promover encontros entre indivíduos que advogam o mesmo sentido de mundo, os mesmos gostos, os mesmos modos de vida e os mesmos estilos de vida. O grande ponto de inflexão, desse modo, ocorre com a constituição de fóruns e redes que têm importância estratégica para ativar expandir e consolidar novos estilos e modos de viver de indivíduos e grupos sociais em uma 
cultura dada, ou de novos projetos para o humano, pensado em escala mundial (Dabas; Najmanovich, 1995).

Redes que provocam situações, redes que lançam novos projetos e estimulam ações, não só na cidade, mas, no mundo urbano contemporâneo, em base local ou em termos globais. Redes que geram movimentos, debates, associações, formas de inserção pela diferença na malha urbana, ampliando, assim, o grau de individualidade e de singularidade no social e construindo novas possibilidades culturais que agem no sentido de instituir estilos, condutas, formas de ser na diferença e entre as especificidades já instituídas no espaço da(s) cidade(s) e além dela(s).

Desse modo, o conceito de grande cidade, e o de metrópole, parece estar conexo à construção social e cultural da realidade urbana contemporânea, dentro de um leque globalizado de opções, onde modos específicos de individuação recortam o societário existente de modo contínuo, estabelecendo novas possibilidades do singular em busca de inclusão social e de sua diferenciação pela fragmentação a seguir. Seja através de formas conflituais, seja em configurações de solidariedade e complementaridade de opções identitárias, ou de gostos, ou de maneiras de viver que se aproximam de outras próximas ou diferentes, em busca de uma marca que as identifique como singulares e específicas.

Discutir estilos de vida e modos de viver no contemporâneo não implica, por outro lado, apenas, o jogo permanente de novas formas de apresentar-se no social pela diferença. Esse perigo, endossado por Benjamin (1985), da ruptura com o passado, para um subsequente e nostálgico e angustiante caminhar para um futuro nunca alcançado, pela presentificação incessante dessa busca do singular e do único, de um futuro sem raízes, pela ruptura abrupta com o passado e com a tradição, e cujo único destino é o caminhar sem fim e à melancolia de Ulisses, que só pode prosseguir sem olhar para trás: olhar para o passado é olhar para a morte, pode ser sentido através de uma visão menos finalista.

Estudos recentes sobre redes sociais de migração (Truzzi, 2008) mostram que esses novos moradores do urbano, que se deslocam do rural ou de cidades grandes para outras mundiais, se quebram a tradição originária com a sua migração, também refundam e recriam as tradições deixadas para trás, no lugar para onde se destinaram. Nesse processo, incorporam ou ajudam a formar no novo lugar redes de encontros onde essa tradição é remixada e ampliada e instrumentalizada de maneira a serem notados como diferença, 
através da tradição reelaborada: como estilo tribal, popular, étnico, musical, comportamental ou que nome que se dê, pelos contemporâneos globalizados. E, mesmo, ajudam a recompor as tradições no seu lugar de origem, com a remessa de dinheiro para a manutenção do social e do cultural local, e do entrecruzamento do local com o global, através de novas técnicas que são incorporadas à tradição, modificando-as ao mesmo tempo em que as asseguram enquanto tradição em movimento.

Se pensarmos na antropologia das formas simbólicas de Sahlins (2003), por exemplo, para quem a cultura, se é produzida na ação, também é alterada na ação, esse embate constante forma significados sempre densos e sempre tensos de recriação permanente. A tradição, desse modo, se é negada enquanto procura de novos espaços de singularidade e de diferenciação, por outro lado, é sempre revisitada no anseio de inclusão das diferenças perseguidas ou assumidas no cultural da tradição em que se originou, no embate infindo entre a cultura subjetiva e a cultura objetiva, ficando como uma referência sempre presente, que liga o novo ao passado e ao mesmo tempo o provoca enquanto releituras e ampliações e mudanças e novos cortes em procuras de estabelecimento de novos processos.

Não apenas provoca elementos nostálgicos do que se perdeu, mas se incorpora no urbano contemporâneo provocando diferenciações e novas formas de se colocar como singularidade. São embates de mão dupla (Giddens, 2002), singularidade e remontagem da tradição, e tradição que inaugura possibilidades novas de diferenciações, ao mesmo tempo em que se revigora com registros originais que a ela se incorporam assim que instituídos, e assim por diante.

Se as grandes cidades continuam a ser o locus privilegiado das diferenciações e da liberdade possível rumo à individualidade, no capitalismo e no Ocidente, por outro lado, o desenvolvimento do sistema capitalista modula uma predominância do novo em todos os registros sociais e culturais de um local. Já no início do século XX, Wirth (1967) dizia da mistura do modo de vida capitalista no campo diluindo as diferenças entre campo e cidade. De duas esferas diferenciadas, passavam a ser um modo contínuo de encontros e desencontros sob o comando do capital e da tecnologia; e sob a hegemonia do urbano o registro de um modo vida rural passava a sofrer, sobretudo, suas influências para o seu próprio reinventar, enquanto tradição e enquanto processo cultural, ao mesmo tempo em que provoca leituras do rural na cidade. 
Isso também acontecendo em todos os modos de vida que passam a ser afetados pelo processo de produção da individualidade no capitalismo. Ver, por exemplo, os casos dos indígenas no Brasil: as tribos remanescentes se utilizam de tecnologia de ponta visual e de pesquisa histórica e linguística para preservarem a sua própria memória: o Centro de Tecnologia Indigenista (CTI) que o diga. Muito de sua produção fílmica atual é realizada pelos próprios indígenas, no registro de suas tradições, mitos, lendas, linguagem, costumes.

Outros tantos grupamentos indígenas são reinventados na modernidade brasileira (bem como outros registros étnicos, como os quilombolas, entre outros): linguistas ensinam a língua perdida pelas novas gerações, historiadores vasculham na poeira dos arquivos costumes e tradições esquecidas e ajudam remanescentes a retomarem as identidades esquecidas ou perdidas e a inserirem-se na modernidade do país: como tradição e como grupo. As redes interconectam instituições, práticas sociais diferenciadas e alargam o alcance das agendas de cada movimento, os lendo e agindo neles, com eles e sobre eles como unicidades que lutam pela reintegração ao tecido social na sua diferença.

A complexidade atual do modo de viver capitalista, sob hegemonia da diferença e sob a dominação dos grandes centros urbanos, oferece visualizações múltiplas de um sistema dinâmico de vasos comunicantes por onde extravasam pessoas, solidariedade, conflitos, dinheiro, informações, projetos e projeções (Costa, 2005). Configura redes que liberam interações horizontais e manuseio e preparo de instrumentos de pressão, e abre palcos de possibilidades novos que transcendem as fronteiras locais, agregando e integrando os associados em um ciclo ampliado de identidades, de estilos, de confiabilidade, de sociabilidade e de ideologias.

Pensar estilos de vida e modos de viver na contemporaneidade, assim, é elaborar exercícios metodológicos e teóricos que deem conta da complexidade do conceito simmeliano de liberdade individual e grupal enquanto cultura subjetiva em crescimento contínuo desde o advento do modo de produção capitalista, primeiramente tendo a cidade como ponto nodal de seu desenvolvimento para a individualização e, depois, logo depois, abarcando as demais formas da cultura de um estado: campo e cidade como contínuo, tradições que se fragmentam e são remontadas a partir das novas informações e tecnologias, memórias que são preservadas, revividas ou reinscritas a partir da inserção no global, e assim por diante. Ou de um país em relação aos demais: na 
globalização criando culturas híbridas, mas ao mesmo tempo possibilitando modos diversos de inserção da tradição na modernidade, ou mesmo, através da parte mais perversa de sua instrumentalização, no individualismo, levando indivíduos e grupos à alienação, à melancolia, à solidão.

\section{Referências}

BENJAMIN, W. A obra de arte na era de sua reprodutibilidade técnica. In: BENJAMIN, W. Obras escolhidas: vol. 1. São Paulo: Brasiliense, 1985. p. 165-196.

CADOZ, C. Les realités virtuelles. Paris: Flammarion, 1994.

COSTA, R. da.Por um novo conceito de comunidade: redes sociais, comunidades pessoais, inteligência coletiva. Interface, v. 9, n. 17, p. 235-248, 2005 .

DABAS, E.; NAJMANOVICH, D. Redes: el lenguaje de los vínculos. Buenos Aires: Paidós, 1995.

DURKHEIM, É. Georg Simmel: Philosophie des Geldes (Philosophie de l'argent). Revista Brasileira de Sociologia da Emoção, v. 1, n. 2, p. 238-241, 2002.

ELIAS, N. O processo civilizador: volume 1. Rio de Janeiro: Jorge Zahar, 1990.

ELIAS, N. O processo civilizador: volume 2. Rio de Janeiro: Jorge Zahar, 1993.

GIDDENS, A. Modernidade e identidade. Rio de Janeiro: Jorge Zahar, 2002.

KOURY, M. G. P. Introdução à sociologia da emoção. João Pessoa: Manufatura; Grem, 2004.

KOURY, M. G. P. Emoções, cultura e sociedade. Curitiba: RCV, 2009.

LEMOS, A. (Org.). Cidade digital. Salvador: EDUFBA, 2007. 
MARTINS, P. H. As redes sociais, o sistema da dádiva e o paradoxo sociológico. Caderno $C R H$, v. 17, n. 40, p. 33-48, 2004.

MEAD, G. H. Mind, self, and society. Edited by Charles W. Morris. Chicago: University of Chicago Press, 1934.

PARK, R.; McKENZIE, R. D.; BURGESS, E. The city: suggestions for the study of human nature in the urban environment. Chicago: University of Chicago Press, 1925.

SAHLINS, M. Cultura e razão prática. Rio de Janeiro: Jorge Zahar, 2003.

SENNET, R. O declínio do homem público: as tiranias da intimidade. São Paulo: Companhia das Letras, 1998.

SIMMEL, G. Philosophie der Geldes. 2. ed. Leipzig: Duncker \& Humblot, 1907.

SIMMEL, G. Simmel e a modernidade. Organizado por Jessé Souza e Berthold Oëlze. Brasília: Editora da UnB, 1998.

TRUZZI, O. Redes em processo migratório. Tempo Social, v. 20, n. 1, p. 199218, 2008.

WAIZBORT, L. As aventuras de Georg Simmel. São Paulo: Editora 34, 2000.

WIRTH, L. O urbanismo como modo de vida. In: VELHO, O. G. (Org.). $O$ fenômeno urbano. Rio de Janeiro: Zahar, 1967. p. 97-112. 